\title{
Encouraging Statistical Learning through Eastern and Western Mathematical History and its Butterfly Effect Consequences
}

\author{
Carson Lam Kai Shun
}

Faculty of Science Department of Mathematics, The University of Hong Kong, Pok Fu Lam, Hong Kong

DOI: $10.36347 /$ sipms.2020.v07i11.004

| Received: 14.11.2020 | Accepted: 26.11.2020 | Published: 30.11 .2020

*Corresponding author: Carson Lam Kai Shun

Abstract

Original Research Article

What are those factors that affect students' academic performance? In this study, it is shown that children's selfefficacy and achievement goals together with their parents' involvement can affect the scholar outcome. This author employs a test in whether (creating meanings) to history context can attract young teenagers in learning mathematics. Moreover, it is also interesting to have a research in its consequences Butterfly Effect (or HKLam Theory). Indeed, for the Singapore's mathematics curriculum, meanings for historical context is used to motivate students for understand difficult mathematics concepts. However, the country lacks the application of these ideas to their daily application. It is no doubt that too much emphasis in applications will lead us into the road of traditional Babylonians - they knew much about numerical mathematics but can't generalise our modern mathematical laws like Pythagoras Theorem. One of the applications of the Butterfly Effect (or HKLam Theory) framework is to help us establish our future digital library. The limitation is an unexpected result may happen where the framework becomes invalid. This can be remediated by using expectance to solve the problem associated.

Keywords: academic performance, learning mathematics, Pythagoras Theorem, digital library.

Copyright $\left({ }^{\circ} 2020\right.$ The Author(s): This is an open-access article distributed under the terms of the Creative Commons Attribution 4.0 International License (CC BY-NC 4.0) which permits unrestricted use, distribution, and reproduction in any medium for non-commercial use provided the original author and source are credited.

\section{BACKGROUND OF THE STUDY}

There is a great deal of research, such as PISA and PIRLS, that studies how students can be helped in achieving better grades in mathematics and compares the differences between countries. From my point of view, the most important question is how our teachers encourage young students to learn mathematics actively. According to this applicant's research at HKU between 2014 and 2015, during their free time, most boys enjoy playing electronic games, while girls prefer chatting on their mobile devices. Therefore, this applicant believes that when one spends too much time using entertainment devices, the parents or guardians will attempt to prevent their use, which can lead to management risks (non-governable) or behavioural problems. In the worst scenario, violence could occur between parents and their children. If this occurs, someone may need to step in and intervene and parents should seek professional advice. It is used to solve conflict between parent and students. The key is to encourage a well-balanced daily life of learning and playing; and help their children study effectively, while developing a good parent-child relationship. Hence, the children's academic performance will improve and they will benefit from "passionate learning" in a fun and relaxed environment.

The aim of this proposed doctoral research is to test whether a distressed environment through making learning more attractive to students will result in greater achievement in mathematics. To do so, one first needs to motivate students' to be interested in reading about mathematical statistics by linking it with the historical background. In addition, one must investigate the "domino effect" (consequences) of such practices (i.e., whether students will read more during their leisure time as opposed to playing). If children's attitudes are positive, then the "domino effect" of rebellion can be prevented, as they perceive their studies to be enjoyable.

Therefore, the research questions are as follows:

1. What are those study problems that affecting our children's learning?

2. Why should we link (create meaning) historical context with mathematical statistics?

3. When will parents try to involve their children's learning? Why

4. How will the (consequences) "domino effect" predict a better achievement and why? 
This study will employ a mix of quantitative and qualitative methods using a web-based assessment system. The research design is as follows:

1. Use of interviews to investigate parenting styles with case studies;

2. Employ survey to study those students' learning problem;

3. Collect both questionnaires and from parents to find out how they can affect academic outcomes;

4. Use National Data Survey to discover parental educational expectations;

The expected outcome is that both schools and parents should create a relaxed environment for their children to learn effectively, instead of resorting to different forms of punishment. The most important thing is to inform people on the importance of creating historical meaning (rather than only studying the physical daily applications or just offering children rewards) in mathematical learning. It should be used to raise children's interest levels, since the historical meanings can help in preventing a "domino effect" (by creating a well-balanced learning and playing lifestyle) and can lead to a more desirable academic effect on students.

\section{Relevant Literature and Guiding Framework}

There are various reasons why it is important to introduce mathematical history into the study of mathematics. This is because the most common method is to treat the subject as purely technical. However, mathematical concepts come from human endeavor. In other words, there are those who look to solve daily societal, environmental, or contextual problems by developing mathematics equations. Hence, one's surroundings have a profound affect, and by understanding cultural context, students will become more easily in understand why and how a one can develop a mathematics topic. As such, students can better apply these mathematical theories. Over time, this disparate collection of mathematical knowledge coalesces to form a language and can be used to understand and rethink the world differently. The most important thing is to explore the origin of each mathematical concept and discover those humanities behind them through every story. Hence students can learn mathematics among her development and understand it. If a student wishes to learn more about geometry, they should first read Euclid's work, for example. Therefore, this author strongly believes that it is vital for Hong Kong to incorporate mathematical history into the subject itself. When one creates meaning (a link) between history and mathematics, it will increase children's passion in learning mathematics as they will better understand the context. In turn, they will be happier when learning and will be able to apply their knew-found knowledge more deeply. Eventually, children should not be "afraid" to learn mathematics anymore. They may even create new developments (ideas) through the learning process. That is, the most significant result is helping our children inherit their own country's (mathematics) language and transform it into their own culture w.r.t society's sole situation. Civilization will then continue to "evolve" from one generation to the next.

It is a common practice in Singapore to incorporate historical context into the mathematics curriculum, where a pentagonal framework is employed [1]. It comprises of five qualities:

1. Attitudes: The affective fields of mathematics learning in the cases of its beliefs and usefulness. Whether one feels enjoyment and interest during learning, will appreciate the beauty and power of the subject, and has the confidence to apply it and the perseverance to solve a problem. Students' learning experience do determine their attitude towards the subject [2]. In other words, mathematical learning should be fun, meaningful, and relevant.

2. Metacognition: The "thinking about thinking" or how can on may obtain the ability to control other's thinking process, together with the selfregulatory of learning [3]. To expose and encourage students to solve and think about problems, help them to plan together and seek alternative means of solving, and to discuss and explain the methods used.

3. Processes: The knowledge skills by which one acquires and applies mathematical knowledge. It is no doubt that those things like reasoning, connections and communication, heuristics and thinking skills, application, and modelling are all essential contributed elements for the knowledge abilities [4].

4. Concepts: The attempt to develop and explore in-depth mathematical ideas with an integrated, complete knowledge without any aspects being isolated. In other words, students

5. Should have a deep understand of mathematical concepts, make good connections and applications, participate actively in learning, and have confidence to apply these concepts.

6. Skills: There needs to be a good balanced between various mathematical skills and the understanding behind semantic mathematics principles.

Where the theme of mathematical problem solving is at the center, the framework can be easily applied at different levels (from Primary to A-level) of mathematics education. It can also set the visional way for how the learning, teaching, and assessment of mathematics can be achieved $[5,1]$. 


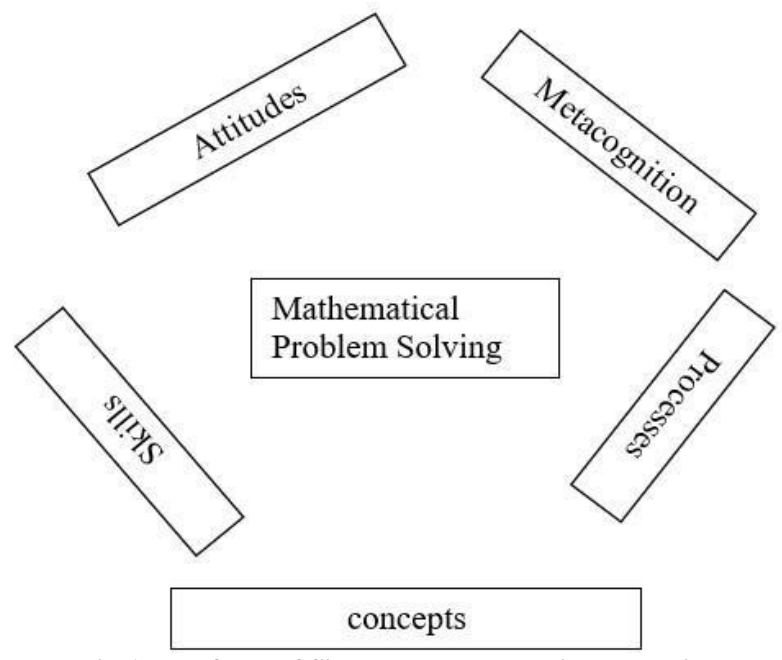

Fig-1: The focus of Singapore Mathematics Education

In addition to raising student interest, one needs to further develop their positive attitude towards mathematics. This comprises several non-quantifiable qualities [6]:

1. one may have beliefs or philosophies in the (usefulness) of the subject [7]. There are two schools of mathematical beliefs (or philosophies) in the case of absolutism - all mathematical knowledge (proofs) is based on beliefs, how it is interpreted, and why it is true; fallibilism -- all mathematics is reduced into lingual (in terms of conventions and rules under the assumption of social convention; interpersonal social processes such that individual mathematical knowledge can be turned into an objective one; and social aspects of reality where objectivity is understood to be social [7].

2. Enjoy learning the subject. What would be the motivations behind the students' learning the subject? What are their beliefs regarding mathematics? How do their emotions affect their learning? Who plans their learning strategies and what are they?

3. Develop an appreciation for the beauty lucidity, simplicity and restraint and power of those mathematical ideas behind [8].

4. Build confidence in using the subject. Make mathematics an everyday adventure, play mathematical games to show its various applications, and re-establish its foundations.

5. One may instil a spirit of perseverance when solving a problem. Attitudes, values, ethics, and morals can stimulate students when working on difficult mathematics problems.

However, there are critics to Singapore's approach to teaching and learning mathematics. Primarily, the main concern is that the country puts less emphasis on the applications of mathematics. The focus is more theoretical and less practical, as in the case of United States. Certainly, it is better to make

mathematics more applicable for children, compared to simple memorisation. A lack of daily applications may lead to the question: "Why do we need to learn mathematics as it hardly applies to daily life?" This could be the real problem facing mathematics education in Singapore. This author believes that there should be a well-balanced equilibrium between concepts, historical context, and applications in the learning of mathematics.

A better, modified mathematical learning philosophy, using the Singapore experience, should be that studying mathematical historical context creates meaning. There will then be motivation to understand, in-depth, the related concepts, as well as the realization for how mathematics can be applied in daily life.

\section{histroic context}

for meaning

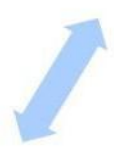

realization of

ideas to apply daily

motivation to

understand

concepts

Fig-2: A proposed framework for a complete Singapore Mathematics learning

An interesting means of studying the connections between mathematical learning and historical context can be found in statistics and probability.

Most people now believe dice were invented in India nearly 5,000 years ago [9]. Very different from the standard cubical dice of today, they were made from either fruit stones or animal bones [10]. dDice were mainly used for fun and gambling. However, they were also used for fortune telling. Ancient people heavily believed in the supernatural power of dice rolling e. It is this cosmogonical attitude which gives us a rough causal explanation of people at that time [11]. There are references to dice throughout history. For example, in Greek mythology there is described a game of dice between Zeus, Poseidon, and Hades. In the Hindu text, Mahabharata, it is explained how the Pandavas took over the kingdom through a game of dice.

Regardless, ancient people had no knowledge of mathematical probability theory. The first permutational and combinational theories began in India and were known as the Bhagavati sutra appearing in around the 3rd or 4th century B.C [12]. 
Modern Western probability (both combinational and permutational) theories were not formulated until the early Seventeen Century [13]. French mathematician Pascal famously asked his friend Chevalier de Mere:

During trials in the throwing a dice for eight times, a player tried to roll for a "1". However, after three unsuccessful ordeals, the test was finally stopped. What should he do for the compensation? [13].

Later, Pascal wrote to Fermat discussing the problem; and it was their resulting correspondence [14] which began mathematical probability theory. A few years later, Christiaan Huygens published On Reasoning in Games of Dice. Meanwhile, Pascal discovered new properties linking the arithmetic triangle with the study of probability:

For all triangles which is arithmetic, when there are two continuous cells located in the identical base, moving from the upper until lower, one will find the number of cells equal the upper to the top base is just the number of cells that measured from lower to the bottom inclusively [13].

This forms the foundation of our modern binomial theorem and so too does Pascal's triangle [15]. However, a Chinese mathematician called Chu Shihchieh discovered as much as far back as 1303 - as described in Precious Mirror of the Four Elements.

\section{RESEARCH FRAMEWORK}

The framework of this research focuses on the Butterfly Effect (or HKLam Theory, Ref: K.S.Lam (2020), Big Data Investigation into the Causes and Treatment of Caries in Kindergarteners, Sch J Phys Math Stat, October, 2020; 7(10): 272-294): The Law of Total Probability Theory (Converse of the Law of Large Numbers), and catalogues random variables together with the Domino Effect. The unexpected results can be supplemented through statistical expectation.

Around the 5th Century A.D., the Roman Empire first used statistics eto empirically estimate its population. Intuitively, the modern concept by Jacob Bernoulli in the early 18th Century was as follows:

When rolling a dice, the empirical probability of continuing Bernoulli trials of getting one (say) will approach to the theoretical probability. Or in terms of symbolic mathematics, the sample average:

$$
\mathrm{Xn}=(\mathrm{X} 1+\mathrm{X} 2+\ldots . .+\mathrm{Xn}) / \mathrm{n}
$$

Will tend to the expected value

$$
\mathrm{Xn} \rightarrow \mu \text { when } \mathrm{n} \rightarrow \infty \text {; }
$$

Conversely, the Law of Total Probability Theory (developed by Thomas Bayes in the late 18th
Century) began by solving the special case (direct problem) as follows:

"[...] where the causes of an event that happens would likely to be a ratio corresponding to the instance of the miscarriage, while the occurrences must employ nearly similar ratio w.r.t. the instance of miscarriage, if there were sufficient number of trials; and the final ratio would tend to the first until infinity, as one gradually increase the number of trials" [16, 17].

Whereas the Bayesian formula is [18]: Let $\mathrm{H} 1, \mathrm{H} 2, \ldots .$. , $\mathrm{HK}$ be $\mathrm{k}$

$P\left(E \mid H_{i}\right)=\frac{P\left(H_{i}\right) P\left(E \mid H_{i}\right)}{\sum_{i=0}^{k} P\left(H_{i}\right) P\left(E \mid H_{i}\right)}$

Mutually exclusive and exhaustive events and $\mathrm{P}(\mathrm{Hi})$ be their (prior) probabilities. Next, assume that $\mathrm{E}$ is an observable event with alternative probabilities relative to the $\mathrm{P}(\mathrm{E} \mid \mathrm{Hi})$. Then, given that $\mathrm{E}$ is observed, the conditional probability of the events $\mathrm{H}_{\mathrm{i}}$ is given by (*).

Clearly, Bayes relates the (following) indirect problem to the development of the "causes" under the consideration of those observed frequencies as depicted below:

"There is a friend [Hartley may refer to Bayes] has discussed with to me about reaching a solution to the converse of the problem [19], [...] under the condition that the trials should be large, the deviation tends to be inconsiderable: This shows that we need to consider the proportions, and, by how much, why there is a sufficient observation according to their effects [20, 17]."

In such a case, Bayes used a material situation for his model. What his model employed is:

i) A parameter (p), which stands for an unknown probability;

ii) A series of data that stimulates the binomial distribution device with parameters $\mathrm{n}$ and $\mathrm{p}$. The result is an integral term for the probability $\mathrm{p}$ with $\mathrm{p} 1$ and $\mathrm{p} 2$ as the lower and upper limits. In fact, Bayes derived the posterior distribution of $p$ after an event $E$. The trial had been continued for $\mathrm{n}$ times with $\mathrm{k}$ successes in an observed Bernoulli experiment. The prior distribution on parameter $\mathrm{p}$ was uniform. Bayes also gave an objective reasoning for such prior distribution. The fact is: as the posterior distribution approaches closer to the point $\mathrm{p}$ and finally converges to it, the prior distribution will gradually lose its influence on the limiting behavior. This is the inverse side of Bernoulli's law of large numbers. 
When one is talking about the source of random variables [21], one usually refers its origin to Andrey Kolmogorov [22]. However, the earliest appearance of such an idea may have come from Laplace in 1781, who devised a formula concerning the assumption on a sum of "quantities variables" in probabilities. In 1829, Poisson developed approximations to probabilities, and discovered that, for various independent experiments, the sum of values that something receives usually states between certain limits. One year later, Hauber - as Poisson's successor - emphasized the difference between "undetermined quantities" and the "values" they each received with a particular probability. A few years later (1867; 1887/90), Chebyshev finally differentiated the "quantities" and the "different values" they can take. Indeed, Chebyshev did not use notation to make a distinction between these "random variables" and their concrete "values". In 1898, Nekrasov concluded that a sum of "random magnitudes" will always take a given value. In general, before the early 20th Century, one could not always explicitly distinguish between random variables and their values. This is similar the terms "estimated value" or "compensation value" in the historical case of least squares [22].

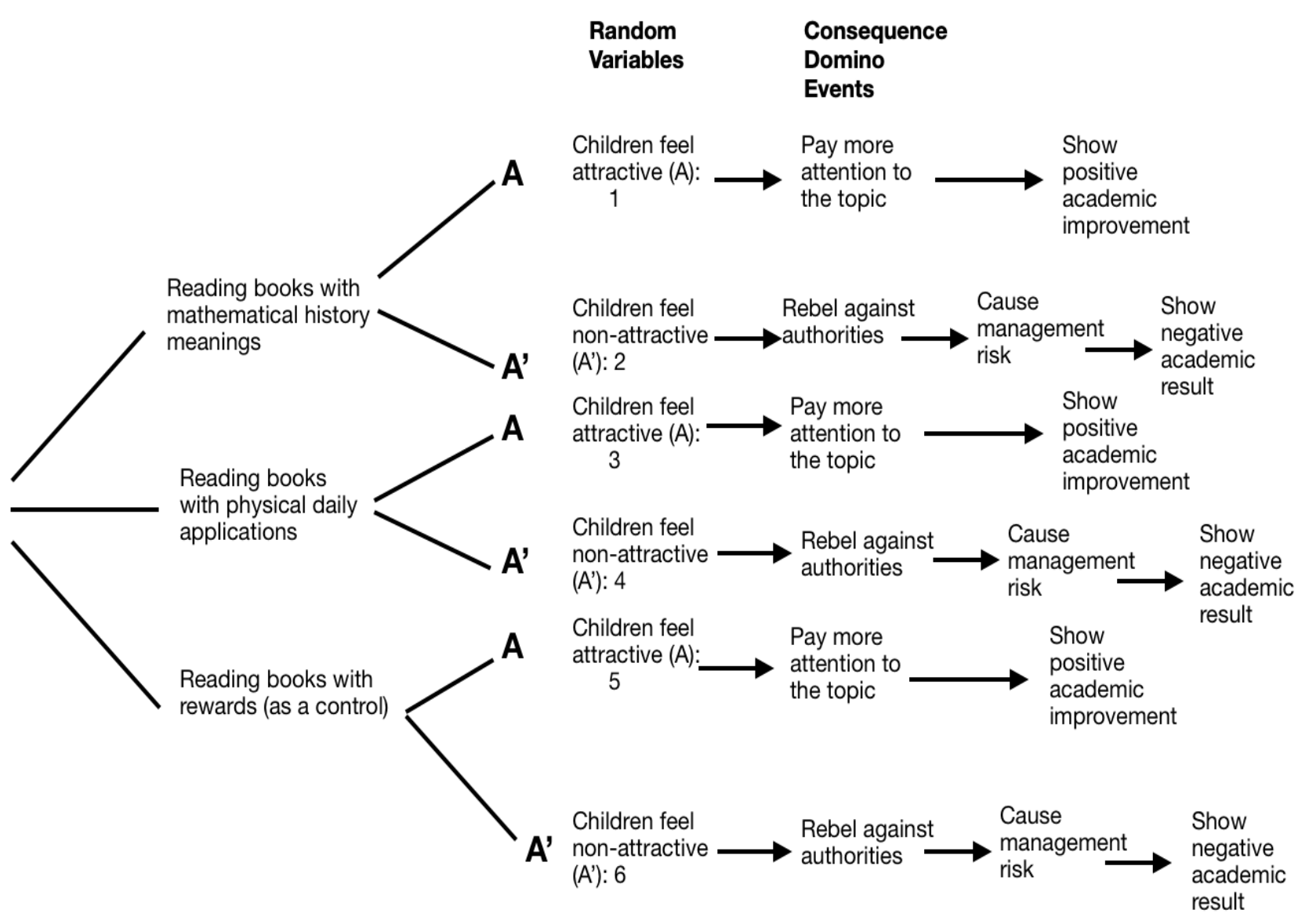




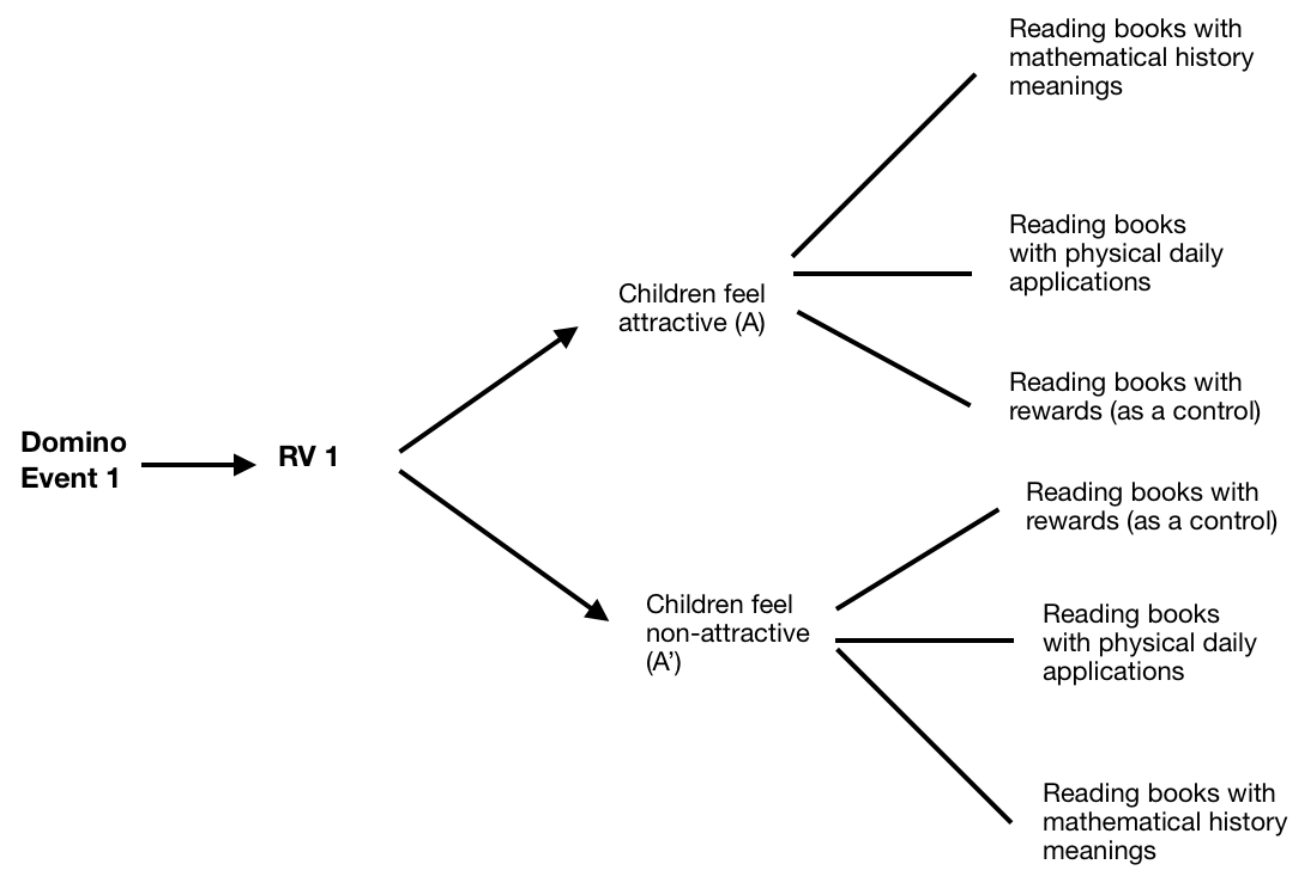

Where Domino Event 1 is: Pay more attention to the topic $\rightarrow>$ Show positive academic improvement (suffices to the path analysis dependency calculation for finding their relationships in between applying Structural Equation Modelling)

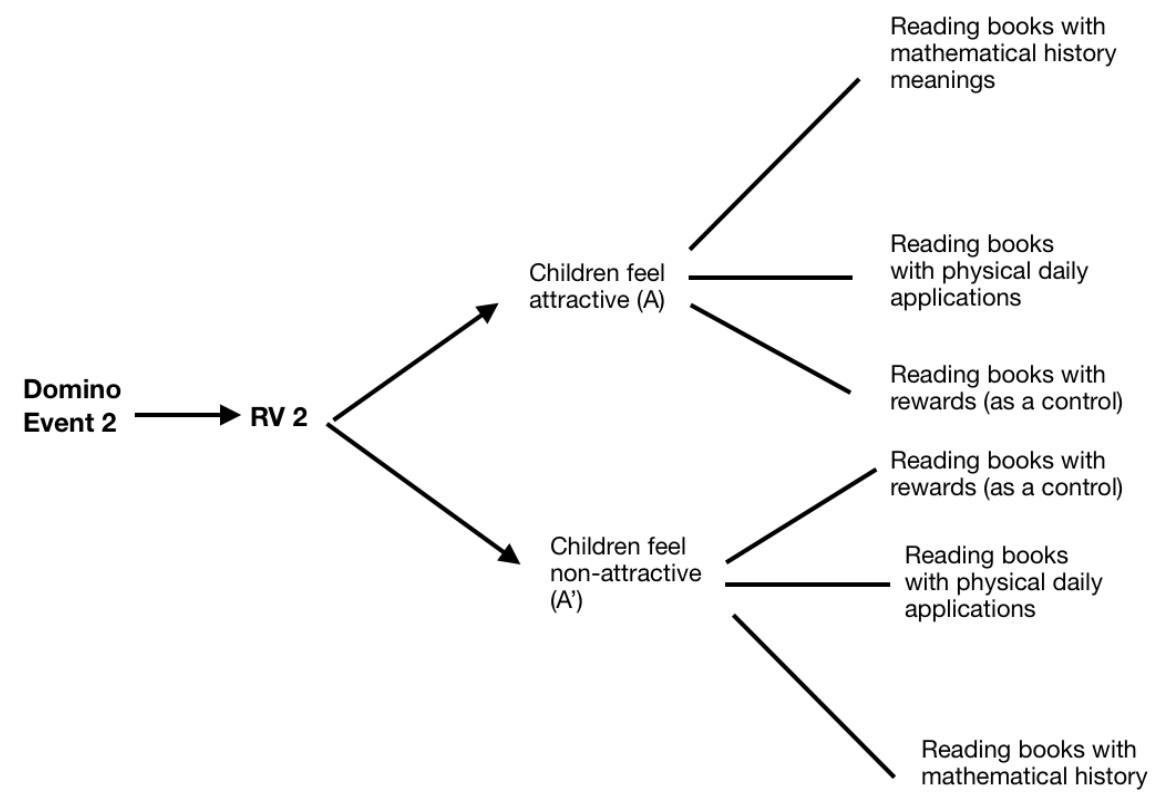

Where Domino Event 2 is: rebel against authorities $\rightarrow>$ Cause management risk $\rightarrow>$ Professional intervention will be needed $\rightarrow$ Show positive academic result

(suffices to the path analysis dependency calculation for finding their relationships in between - using Structural

田

Fig-3: A proposed HKLam (Net-Seizing) Theory — possibilities of children's mathematical learning attractiveness and their consequences 
The next principle used in my philosophy is the domino effect. The domino effect is a chain reaction in a linear order, where one small piece falls, setting the rest in motion. One of the best cases to demonstrate Domino effect is Mathematical Induction. The word "domino" was first connected to religious purpose. Indeed, it is a kind of "hood worn by the canons of a cathedral church". Later, the term was linked to the widely-known board game which is a delicious pizza.

However, no one can tell how exactly the connections. Most people speculated that this may be come from the fact that: When Italian missionaries who travelled to China and saw a similar game together with they brought it back to Italy. A cultural exchange case

$\begin{array}{ccc}\text { Integers } & \text { Even } & \text { Odd } \\ 1 & 0 & 1 \\ 2 & 2 & 3 \\ 3 & 4 & 5 \\ 4 & 6 & 7 \\ 5 & 8 & 9 \\ 6 & 10 & 11 \\ 7 & 12 & 13 \\ . & . & \cdot \\ \cdot & \cdot & \cdot \\ . & . & . \\ \mathrm{n} & \mathrm{E} & \mathrm{O}\end{array}$

Maurolycus discovered that any number in a row will be preceded by any number in the following row. The triangular number 15 is followed by the even number 6 , for example. In general, two of the propositions Maurolycus made are as follows:

"The odd numbers are obtained from unity by successive additions of 2 " I.e. On $+2=\mathrm{On}+1$ "Each integer plus the integers before will equal to the corresponding collateral number [24]." i.e. $n+(n-1)=$ On

Obviously, the above forms the elementary prototype of mathematical induction (by finding the induction pattern - from a special one to a general case). When one gradually transforms an individual number into a common term together with using methods such as summation, it provides a general final answer - it has been "induced". If one of the terms is correct, the following will also be true. The result is like a row of well-ordered books in a library. When the first book is knocked over, it will hit the second one, and so on, with the rest falling in sequence. This is the basic idea of mathematical induction which functions just like the "Domino Effects". between ancient Eastern and Western civilization. Finally, it evolves to our present game after mixing and combining with local Western culture.

Indeed, the origin of mathematical induction was introduced by the Italian Maurolycus in 1494 . He developed a treatment of the polygonal and polyhedral numbers. In his book he defines different numbers such as odd, even and triangular. In addition there are also numbers defined as square, number on the other side which is longer, etc. The definition of a triangular number is: one sums up inclusively from integer 1 to integer $\mathrm{n}$ while the nth number on the other side which is longer: $n(n-1)$. He obtains the relationships among these numbers that is shown below as in the table [23]:

$\begin{array}{ccc}\text { Triangular } & \text { Square. } & \text { N.P.A.L. } \\ 1 & 1 & 0 \\ 3 & 4 & 2 \\ 6 & 9 & 6 \\ 10 & 16 . & 12 \\ 15 & 25 & 20 \\ 21 & 36 & 30 \\ 28 & 49 & 42 \\ . & . & \cdot \\ . & . & \cdot \\ . & . & \cdot \\ \text { T } & \text { S } & \text { L }\end{array}$

The Butterfly Effect (or HKLam Theory) explains how even a minor change can result in large differences over time.

My HKLam (Net-Seizing) Theory (Figure-3) consists of three parts:

1. Conditional Probability: Is used to test whether students will be attracted by linking the initiative to learn through creating mathematical meanings within a historical context. This will be compared with the daily applications of mathematics together with offering them rewards.

2. Random Variables: It takes two values, which are either number one (attractive) or number two (non-attractive). This acts as a bridge to connect the non-linear (nondeterministic) conditional probability part to the later linear part (domino effect).

3. Domino Effect: The first part assumes that a student is attracted by the former conditions, and hence will pay more attention during their study. As such, the student might achieve a better grade. The second part assumes that a student is not attracted by the former conditions. Therefore, a series of consequential actions will occur until external 
intervention is needed to change the serious situation.

The Theory can then be used in converting all the non-linear matters into the linear through a choice of random variables. If one can use the probability and combinatorics etc to list all the possible outcomes, the corresponding consequences are also mapped with random variables together with the previously probability, the whole process will be highly related to what one may call "Butterfly Effect". Thus, the described action is just like catching a butterfly (probability part) with the corresponding domino consequences (since different possibilities will give different action and the consequence actions).

If one can make the good use of the all different probabilities during small changes in things and their consequences, one will know what all possible outcomes were. Hence, one may catch the wanted butterfly.

\section{RESEARCH METHODOLOGY}

Mixed methods have been applied to this current research to investigate the complexity of the author's proposed HKLam Theory referenced to the behaviour of students. This paper will also discuss the philosophy of research for this subject. The author will also employ a logistics type of research model, which includes five main streams: hypothesis setting, focus interviews, surveying, a design of the required questionnaire together with the variables testing [25]. Actually, the final [26] section will be well implemented by using a structural equation model as a means of data analysis.

\section{A Brief Review in the Philosophy of Research}

In order to establish facts or reach new conclusions, one should apply a systematic process of collecting, analysing, and interpreting related information or data to achieve a better understanding of a particular subject [27].

\section{Logistics Research Model, Settings and Participants, Data Collection and Analysis}

A logistics research model has been adopted to test whether or not this proposed HKLam Theory of this study is valid. It is suggested that this type of philosophy can be verified through the following five stages:

\section{THE HYPOTHESES}

The research is an extension of the framework that was highlighted in the previous section. The study variables (dependent / independent) are based on Bayesian's theorem (the first part of this study's proposed HKLam theorem) so as to derive the hypotheses. Furthermore, this paper aims to better understand how one can increase student's motivation during the daily life in learning mathematics. The design in the setting of the hypothesis and all of the details in the process of measurement are mainly based on the [28] author's suggested HKLam Theory, which is shown as a particular case in Figure 3. Hence, this applicant suggests the following hypotheses:

Hypothesis 1: Students are attracted to mathematics if the teacher provides books that relate to the historical context of the subject;

Hypothesis 2: Students feel bored when they read about mathematics in a historical context; Hypothesis 3: Students are willing to spend more time reading physical (information technology) daily application books that are linked to mathematics;

Hypothesis 4: Physical daily application (information technology) mathematics books do not promote students' interest in learning mathematics;

Hypothesis 5: The rewards encourage students to read more mathematics books;

Hypothesis 6: The rewards do not encourage students to read more mathematics books;

Hypothesis 7: Once students are motivated, they will pay more attention to studying mathematics;

Hypothesis 8: If students are bored, they will require professional intervention;

Hypothesis 9: When students enjoy studying mathematics, there is improvement in academic results;

Hypothesis 10: After intervention, students will show an improvement in academic results; Hypothesis 11a: The success of learning mathematics is positively related to student obedience;

Hypothesis 11b: The success of learning mathematics is positively related to parents' management risk among their children;

\section{Designing the questionnaire}

The questionnaire consists of four sections: school information, type of position (principal, teacher, etc.), background of students, and parents. In fact, school information will help to gain a better understanding of a particular school's organisation, such as historical events and overall profile. Additionally, this will also help to determine the economic backgrounds of the schools related to this study. For the students, the main focus of investigation is referenced to their attraction to books borrowed from the school library, such as mathematics books with a historical context, physical (information technology) daily application mathematics books, or reading mathematical books with rewards. For the parents, the effects of child rebellion and management risks will be considered. Finally, school teachers may seek to better understand the importance of improving academic results and how this can be ultimately achieved.

Focus interviews - a collection of qualitative data 
The focus interviews provide an exceptionally valuable opportunity to gather more information about the parents' view of their children's rebellion, together with their response when they face managerial risks. For an in-depth study, these research ideas could be extended to a wider audience, such as teachers and principals. All of the aforementioned research results will be used for this paper's philosophy validation and triangulation.

Indeed, focus interviews could be used to collect qualitative data. More precisely, focus group interviews are "a group that consisted of different individuals with a certain characteristics and they will concentrate in a particular issue or a special topic" [29, 30]. In addition, "a focus group is indeed a small group of people, with number of six to nine. They are brought together by a well trained researcher who will help them explore the perceptions, attitudes, ideas and feelings during the process of discussing about a selected topic" [31, 32]. An interview tries to collect high level of data inside a chosen social context [33, 34] for a specific problem from those of participants' view point being investigated $[35,36]$.

\section{The Surveying Stage - A Collection of Quantitative Data}

This applicant will hosted a web-based survey for all of the school students and parents in Hong Kong. This applicant will send email invitations to all primary and secondary schools for the proposed investigation. The respondents are then required to respond for most of the questions through the usage of a five-point Likert scale [37]. The collected quantitative data will thus be applied during the progress in the establishment of a model. Moreover, the model will also be examined backwards by the data such that one can determine how well our computed model in fitting with those data collected previously [38]. Structural equation modelling will be used as a way of analysing those collected quantitative data.

There are several advantages over other kinds of research methods. First of all, data can be collected simultaneously from a large group of contributors in a fast, simple and cost efficient way. This event happens when one tries to compare with the methods like faceto-face interviews [39-42]. Secondly, one can design of a simple and easy survey for interviews as well as those of the administrative skills required [41]. Thirdly, one can keep a higher level of respondents' data in a secret way. This is because the researchers will always keep their promise in handling data with anonymity and confidentiality that written within the covering letter [43].

\section{The Testing Variables Stage}

Finally, there will be the data analysis section. This applicant will employs those data collected from the survey section for the structural equation model. In the first sub-stage, $\mathrm{R}$ will be used for the purpose of descriptive statistics about the respondent and the preliminary data analysis. This may include those missing value, outliers and extreme values, mean and standard deviation, multicollinearity and skewness. During the second sub-stage, I will apply the Structural Equation Modelling (SEM) in the testing and examination about the relationships among different variables [44]. These variables are associated with my suggested HKLam Theory. In fact, the structural equation modelling (SEM) which is also known as path analysis, covariance structure analysis, simultaneous equation models. It is used to test and examine the hypothesised relationships among variables within the proposed conceptual philosophy. Indeed, SEM is an example of second generation of multivariate analysis. SEM differs greatly from first-generation factor analysis or the regression one. SEM is used as a statistical way. During the process, for a group of multiple independent and dependent variables will be tested and estimated. The final result is the establishment with a list of hypothesised relationships for these variables [45, 46]. Most likely, the dependency among the variables (such as relationship of management risk and level of rebellion between the attraction of children etc) in this applicant's proposed domino events (second part of my suggested theory) can thus be modelled through SEM.

\section{Research Results and Discussion}

This research focuses on the domino sequences of children's behaviour towards reading books. The aim is to test whether or not the proposed HKLam Theory is valid. If the domino sequence is true, future behavioural data may be predicted based on the collected data and then related back to the converse Bayesian probability theory. Hence, one may calculate the future government expenditure for the educational sector. If the proposed philosophy is invalid, the experiment will need to be improved or reconstructed. However, the most important point is that the potential crisis of the nonattractive domino sequence from students' learning could be identified. As a result, it would be possible to suggest suitable professional intervention to the family to prevent a possible tragedy such as fighting between children and parents.

Sukor et al., [47] show that only two motivation factors, self-efficacy and achievement goals, play a significant role in affecting students' academic outcomes. Glynn et al., [48], also mention why selfefficacy can have a strongly effect in the students' academic performance [49]. This event is because when students feel confident in a subject and are unafraid of assessment, they are more motivated to learn [48]. With regard to achievement goals, the best academic results can be attained when students' curiosity and interest is maintained, deep learning strategies are employed, and they study testable and important topics Erica et al., 2014. Obviously, if students lose their curiosity or 
confidence, their academic performance will decline. Thus, one needs to determine whether historical meaning can help maximise students' self-efficacy and achievement goals (see, Lam, 2018 for the research design) [50].

Parents begin monitoring their children because they have certain educational expectations. For example, they may expect a specific level of academic achievement so that their child can obtain a university degree. According to "Child Trends", 64\% of parents expected their children to attain a university bachelor's degree or higher in 2012. This was down 5.5\% from almost $70 \%$ in 2007 and $65 \%$ in 2003 . Hence, in order to induce an improvement in their children's academic results and meet what they want to achieve, parents are always participating themselves in the competitive academic lives among their children. One may relate such kind of influence on students' academic achievements to the parenting styles [51]. Odongo and Ganiron in 2017 highlights that over $60 \%$ of young teenagers agreed that overly strict family rules were one of the major factors in them rebelling. In addition, $74 \%$ of teenagers [52] wanted to seek more freedom/independence from their parents. When there is a challenge to (authoritarian) parents' monitoring behavior, a likely outcome is conflict (negative effects) between the parents and their child. When conflict becomes violent, external professional intervention, i.e., a social worker, may be required [53]. Research shows that parental involvement does also have positive effects on children's academic results.

If a child spends too much time playing it can result in poor academic results. Subsequently, increased parental involvement may occur since parents have certain expectations about their child's education. However, overly strict monitoring might lead to rebellious behavior on the part of the child. Therefore, it is important for children to have a balanced equilibrium between learning and playing. In the following part, this study will discuss in more detail the four types of parenting style:

\section{Authoritarian}

Whenever the child misbehaves, the only feedback the parent provides is through punishment. Furthermore, there is no reward for positive behavior. This kind of style can have a negative effect [54]. For example, in Sarwar [55], Mother A points out that: "For those parents who adopt the authoritarian style, there will be a negative impact that posed upon the behavior towards their own children [56].”

She goes on to say: "I know of a child who is a student of fourth standard having very rude behavior with his peers in classroom. Teachers around him tried their level best to counsel him but a positive result never came. Once a newly appointed teacher realised that there should have been something wrong with this child that was associated with his home or environment he got at home. So, she tried to investigate the matter and realised that his mother punished him using fire and even he showed the sign of his burnt body. The teacher tried to call his mother with the inquiry about the story behind the matter. The teacher finally concluded that his mother usually punishes him in the wrong means [57] and ways (having no communication/discussion to make him aware of his mistakes at all); the boy would then consequently rebel. He then adopted those negative behaviour and remained with a jealous attitude when handled with his peers [58]."

The above narrative matches Ganiron's results for young teenagers, who finds that they usually rebel against the strict rules of the family and seek more freedom. As a result, parental management risk will occur. Mother A's conclusion is that: "[An] authoritarian parenting style where parents are with very strict behavior will always cause their children to become delinquent, when young people tend to be rebellious [59]. They often contradict and retaliate to most of guidance that given by their parents."

\section{Neglectful}

Parents usually show a little of involvement and less strict in handling their child [60, 61]. "Your child has a lot of homework and school projects that are too difficult and vast for them to complete alone. You are not allowed to offer any assistance or guidance even they ask for help. Your child may end up scoring poorly in academic but you are not concerned with his / her performance."

\section{Authoritative}

Parents provide guidance to their children in an issue-oriented and rational manner [62]. According to an interview with a principal in Odongo [63]:

"Authoritative parents seem to be very responsible and reliable. They place much attentions and focus in their children's academic performance, they always visit the school and check on their children [64]. Furthermore, parents will encourage [them] and hence [they] are always there for their academic needs, and this event makes their children perform well, not only [academically] but also [65] [socially]."

\section{Permissive}

Parents show lesser degree of demanding-ness and request a much higher requirement of responsiveness [66]. In Sarwar [55], Mother B claimed that:

"All of the permissive parents will concern and place negative impact to the behavior of children. Parents should not become lenient about their children such that they need to ignore every good or bad act [67]." 
Odongo [63] shows that different parenting styles may have different effects on students' academic achievements. Using a Pearson correlation coefficient (r), Chonge [68] finds that authoritative parent has the strongest positive relationship with mathematical achievement: for those authoritative, $r$ equals 0.65 while for the authoritarian, $\mathrm{r}$ equals 0.55 , in the case of neglectful, $r$ equals 0.21 and permissive, $r$ equals 0.301 [69]. Simultaneously, the coefficient of determination (r2) for parenting styles versus student achievement in mathematics is:

1. Authoritative equals to 0.423 ;

2. Authoritarian equals to 0.3025 ;

3. Neglectful equals to 0.0454 ; and

4. Permissive equals to 0.0906 [70].

This means students' mathematical achievement attained its maximum value at $42.3 \%$, which is just the case that was influenced by an authoritative parenting style.

In brief, parents usually involve themselves in their child's education because they have certain expectations. Motivational factors are crucial in encouraging children to learn and achieve better outcomes. However, if parents enforce overly strict rules (authoritarian parenting), it can lead to rebellious child behavior. In such case, professional social workers might be required in certain cases of overly strict parenting. Nevertheless, it should be noted that authoritative parenting can also result in significant improvements in academic achievements. Therefore, motivational factors and different parenting styles both influence academic results. It is important to determine what factors - historical context, technical application, or positive rewards - may influence motivation.

These prove the correctness of most (predictive) domino effects since:

1. lower in academic performance results more parents' monitoring as they have expectations in education;

2. extremely strict rulings naturally lead to children's rebellious actions;

3. professional intervention will then be needed;

4. suitable parents' controlling indicates an improvement in adolescents' scholar achievements by the above quantitative and qualitative outcomes.

\section{RESEARCH SIGNIFICANCE}

The method of Japanese tofu cutting is nondeterministic and random process. Indeed, the proposed HKLam Theory can then be applied in the process such that one can catch a butterfly with combinatoric, inclusion-exclusion principle, and system of distinct representatives (HKU, Algebra II, 1994 - 1995). Hence, one can find the best cutting route. As a result, one can maximise data storage through a suitable random cut. One may further perform a large amount of data searching and sorting issue of a complex data cube. One can then establish our future digital library. From mathematical representation theory, the corresponding social representation theory suggests that schools have different cultures. Or through those discovered data, one may finally verify this applicant's suggested philosophy of learning mathematics in Singapore and those interactions between historical meaning creation, motivations to understand concepts and realisation of daily applications in the studying. A similar idea of catching a butterfly can be applied in a school's computer system. Teachers can handle students' achievement records in an easier and better way and thus will provide suitable assistance to their pupils. In addition, one may apply the suggested HKLam Theory to catch the non-linearity in the subject of linguistic prediction. Finally, this author suggests that there is a need to develop "passionate learning" model for our guidance / parents. It is used as a reference to help supervise their children's playing and learning in a balanced way. Eastern and Western cultures might have different perspectives on this matter, such that the model may not be applied in all cases. However, one should consider the "passionate learning" (parental supervision) model as a guideline only. This may help to resolve conflict and reduce violence, together with their own traditions [71].

\section{LIMITATIONS}

The philosophy of this study is not perfect. Firstly, there are always unexpected things happened when one tries to catch a study willingness butterfly. This author suggests using statistical expectancy to handle any errors that may occur. Another concern is that everyone has their own characters and expertise. As such, one cannot consider academic behaviour as a factory product with one universal model. By doing so, one may easily fall into the trap of endless ethical struggles or debates. One may solve this issue by considering the "passionate learning" (parent supervision) model as only a guideline. This should be supplemented by a country's traditions and values. In the worst scenario, one might need to employ a tailormade model from professionals. In addition, too much focus in learning daily application, students may lack the competence to generalise mathematical rules. One of the case studies is the ancient Babylonians who had difficulties in concluding Pythagoras' Law but advanced in the triples' numerical application calculations. In practice, one should compare different countries' mathematics learning focus, pros and cons together with the best philosophy behind. Certainly, there are still some common topics that pupils must learn from a mathematical curriculum - algebra, statistics and geometry etc. Finally, the meanings behind historical context in mathematics may not fulfil those high achievement students, philosophical meaning behind each mathematical topic and those scientific explanations will then be employed in such case. 


\section{REMARKS}

I note that there are various factors that affecting parenting style. These factors may include family traditions, personality and personal circumstances [72] etc. However, by learning the cultural differences in parenting, one can obviously prove that he/she is doing the right things in the home. This event may provide some better alternatives for all of the things that he/she wants to change.

\section{REFERENCE}

1. Ho, W. K. (2008). Using history of mathematics in the teaching and learning of mathematics in Singapore, Department of Mathematics and Science Singapore Polytechnic, Singapore.

2. Ministry of Education, Singapore. (2007). Mathematics Syllabus Primary. Retrieved from www.moe.gov.sg/docs/defaultsource/document/ed ucation/syllabuses/sciences/files/2007-

mathematics-(primary)syllabus.pdf

3. ibid

4. Ministry of Education, Singapore. (2007). Mathematics Syllabus Primary. Retrieved from www.moe.gov.sg/docs/defaultsource/document/ed ucation/syllabuses/sciences/files/2007mathematics-(primary)syllabus.pdf

5. ibid

6. Ministry of Education of Singapore. Statute: Compulsory Education Act, 2000. Ministry of Education of Singapore. Lower secondary mathematics syllabus, 2007. Ministry of Education of Singapore. Mathematics: Higher 2 (syllabus 9740), 2007. Ministry of Education of Singapore. Mathematics Syllabus Primary, 2007.

7. Steve, B. (1996). Beliefs Shape Mathematics Spectrum. 28(2):131-141.

8. Cairbre, F. O. (2009). The Importance of Being Beautiful In Mathematics, IMTA Newsletter, 109.

9. Deacon, D., Bryman, A., \& Fenton, N. (1998). Collision or collusion? A discussion and case study of the unplanned triangulation of quantitative and qualitative research methods. International Journal of Social Research Methodology, 1(1), 47-63. doi: 10.1080/13645579.1998.10846862

10. Dandoy, J. R. (2006). Astragali through time. Integrating zooarchaeology, 131-137.

11. Vallverdú- Queralt, A., \& Lamuela- Raventós, R. M. (2016). Foodomics: A new tool to differentiate between organic and conventional foods. Electrophoresis, 37(13), 1784-1794.

12. Gabbay, R. A., Bailit, M. H., Mauger, D. T., Wagner, E. H., \& Siminerio, L. (2011). Multipayer patient-centered medical home implementation guided by the chronic care model. The Joint Commission Journal on Quality and Patient Safety, 37(6), 265-273.

13. Merzbach, U. C., \& Boyer, C. B. (2011). A History of Mathematics, Third Edition, Wiley.
14. https://atiekubaidillah.files.wordpress.com/2013/0 3/a-history-of-mathematics-3rded.pdf

15. Gullberg, J. (1997). Mathematics, From the Birth of Numbers, W.W. Norton \& Company.

16. http://web.math.ku.dk/ sjo/papers/HaldBook.pdf

17. Hartley, D. (1749). Observations on man.

18. Borovenik, M., \& Kapadia, R. (2014). A Historical and Philosophical Perspective on Probability Advances in Mathematics Education Probabilistic Thinking, 7-34. doi: 10.1007/978-94-007-7155$0 \_2$

19. https://link.springer.com/chapter/10.1007\%2F9780-387-46409-1_4

20. https://www.ece.uvic.ca/ bctill/papers/mocap/Zab ell_1989.pdf

21. http://web.math.ku.dk/ sjo/papers/HaldBook.pdf

22. Fischer, H. (2011). A History of the Central Limit Theorem: From Classical to Modern Probability Theory, Springer.

23. http://mathshistory.standrews.ac.uk/Biographies/Maurolico.html

24. ibid

25. Sundarakani, B. (2016). Designing a framework and research model for the logistics service providers innovation and adoption, University of Wollongong in Dubai - papers.

26. http://network.bepress.com/explore/?start=113520

27. Paul, D. L., \& Ormrod, J. E. (2014). Practical research: Planning and design. Pearson Education.

28. https://ro.uow.edu.au/cgi/viewcontent.cgi?article= $1801 \&$ context=dubaipapers

29. https://dergipark.org.tr/uploads/files/b50e/4c3a/90 35/5ae77813ef0de.pdf

30. Anderson, J. C., \& Narus, J. A. (1990). A model of distributor firm and manufacturer firm working partnerships. Journal of marketing, 54(1), 42-58.

31. 15https://repository.up.ac.za/bitstream/handle/226 3/71050/Chisi_Lobola_2018.pdf?isAl=\&sequence $=1$

32. Denscombe, M. (2007). The good research guide for small scale research.

33. 16https://www.bzu.edu.pk/PJSS/Vol33No12013/P JSS-Vol33-No1-16.pdf

34. Patton, M. Q. (2002). Two decades of developments in qualitative inquiry: A personal, experiential perspective. Qualitative social work, 1(3), 261-283.

35. ibid

36. Khan, M. E., \& Manderson, L. (1992). Focus groups in tropical diseases research. Health policy and planning, 7(1), 56-66.

37. https://ro.uow.edu.au/cgi/viewcontent.cgi?article= $1801 \&$ context=dubaipapers

38. ibid

39. Zikmund-Fisher, B. J., Hofer, T. P., Klamerus, M. L., \& Kerr, E. A. (2009). First Things First. The Patient: Patient-Centered Outcomes Research, 2(4), 221-231. 
40. Bryman, A. (2008). Why do researchers integrate/combine/mesh/blend/mix/merge/fuse quantitative and qualitative research. Advances in mixed methods research, 87-100.

41. Sekaran, U., \& Bougie, R. (2011). Business Research Methods: A skill-building approach. Chichester: John Wiley\& Sons Ltd.

42. https://arxiv.org/pdf/1607.01492.pdf

43. ibid

44. ibid

45. Gefen, D., Straub, D., \& Boudreau, M. C. (2000). Structural equation modeling and regression: Guidelines for research practice. Communications of the association for information systems, 4(1), 7.

46. https://bura.brunel.ac.uk/bitstream/2438/11247/1/F ulltextThesis.pdf

47. Sukor, R., Mohd A. A. F., Norhasnida, Z., \& Nor, K. A. R. (2017). Influence of Students' Motivation on Academic Performance among Non-Food Science Taking Food Science Course; International Journal of Academic Research in Progressive Education and Development.

48. Glynn, R. J., Danielson, E., Fonseca, F. A., Genest, J., Gotto Jr, A. M., Kastelein, J. J., ... \& Nordestgaard, B. G. (2009). A randomized trial of rosuvastatin in the prevention of venous thromboembolism. New England Journal of Medicine, 360(18), 1851-1861.

49. http://www.oecd.org/education/school/ImprovingSchools-in-Sweden.pdf

50. McArthur, T., Lam-McArthur, J., \& Fontaine, L. (Eds.). (2018). Oxford companion to the English language. Oxford University Press.

51. http://iiste.org/Journals/index.php/JEP/article/dow nload $/ 30823 / 31646$

52. Ganiron, T. A. S. (2017). Evaluating the Factors Affecting High School Student Rebellion; World Scientific News.

53. Rambaut, A., Lam, T. T., Max Carvalho, L., \& Pybus, O. G. (2016). Exploring the temporal structure of heterochronous sequences using TempEst (formerly Path-O-Gen). Virus evolution, 2(1), vew007.

54. Kerr, M., Stattin, H., \& Özdemir, M. (2012). Perceived parenting style and adolescent adjustment: revisiting directions of effects and the role of parental knowledge. Developmental psychology, 48(6), 1540.
55. Sarwar, S. (2016). Influence of Parenting Style on Children's Behavior; Journal of Educational Development.

56. https://www.researchgate.net/publication/3114511 84_Influence_of_Parenting_Style_on_Children \%2 7s_Behaviour

57. https://mafiadoc.com/articleeric_5b7c9ce8097c47405d8b4580.html

58. ibid

59. https://www.researchgate.net/publication/3114511 84_Influence_of_Parenting_Style_on_Children\%2 7s_Behaviour

60. Kremers, S. P., Brug, J., de Vries, H., \& Engels, R. C. (2003). Parenting style and adolescent fruit consumption. Appetite, 41(1), 43-50.

61. ibid

62. Larzelere, R. E., Morris, A. S. E., \& Harrist, A. W. (2013). Authoritative parenting: Synthesizing nurturance and discipline for optimal child development (pp. ix-280). American Psychological Association.

63. Odongo, A. A. (2016). Influence of Parenting Styles on the Adolescent Students' Academic Achievement in Kenyan Day Secondary Schools; Journal of Education and Practice.

64. http://iiste.org/Journals/index.php/JEP/article/dow nload/30823/31646

65. http://iiste.org/Journals/index.php/JEP/article/dow nload/30823/31646

66. https://www.researchgate.net/publication/3114511 84_Influence_of_Parenting_Style_on_Children $\% 2$ 7s_Behaviour

67. ibid

68. Chonge, H. M., Barasa, P. N., \& Chonge, B. M. (2016). Influence of parenting styles and selfconcept on students' achievement in mathematics: a case study of Kaplamai Division, Trans Nzoia country in Kenya. International Journal of Scientific Research and Innovative Technology, 3(3).

69. http://41.89.160.13:8080/xmlui/bitstream/handle/1 23456789/1665/Benson.pdf?sequence $=1$

70. ibid

71. https://www.ncbi.nlm.nih.gov/pmc/articles/PMC4 174375/

72. https://www.hellomotherhood.com/article/562289role-of-culture-in-the-influencing-of-parentingstyles/ 